\title{
AC/TiO2/Rubber Composite Sheet Catalysts; Fabrication, Characterization and Photocatalytic Activities
}

\author{
Chaval Sriwong ${ }^{1, a}$ and WorapolTejangkura, ${ }^{2, b}$ \\ 1,2 Department of Chemistry, Faculty of Science, King Mongkut's Institute of Technology Ladkrabang, Chalongkrung Road, Ladkrabang, \\ Bangkok 10520, Thailand
}

\begin{abstract}
The $\mathrm{AC} / \mathrm{TiO}_{2} /$ Rubber (ACTR) composite sheets weresuccessfully fabricated by a simply mixing of fixed $\mathrm{TiO}_{2}$ suspension and natural rubber latex $(60 \% \mathrm{HA})$ contents withthe varyingamounts of activated carbon (AC) suspension, followed by stirring,pouring into apetri dish mold, drying at room temperature (RT), after that taking out from a mold, reversing and drying again at RT. Then, the as-fabricated ACTR composite sheets were characterized by X-ray diffractometer (XRD), attenuated total reflectionFourier transform infrared spectroscopy (ATR-FTIR), energy dispersive X-ray spectroscopy (EDS) and scanning electron microscopy (SEM)techniques. The photocatalytic efficiencies of allACTR composite sheet sampleswere evaluated by photodegrading of methylene blue (MB) dye solution under UV light irradiation. The results showed that the photocatalytic activity of ACTR sheet with $10.0 \mathrm{wt} \% \mathrm{AC}$ loadinghas the highest efficiency for the photodegradation of MB dye than the other sheets. This is due to the fact that it is relatively with the synergistic effect of well-combined titanium dioxide catalyst and activated carbon adsorbent.
\end{abstract}

\section{Introduction}

Dye pollutants produced from the various industries are becoming major sources of environmental contamination leading to the water pollution. Although the traditional treatment methods such as chemical coagulation, activated sludge, trickling filter and carbon adsorption have been widely utilized for decolorization of dyes but which have difficulties in the destruction of dye pollutants due to their complex structure, most of dye are recalcitrant $[1,2]$. In the pastfew decades, the applications of heterogeneous photocatalysis using semiconductor materials for environmental protection, purification and remediation have been attracted much attention [3]. Among of the semiconductingcatalysts, titanium dioxide or titania $\left(\mathrm{TiO}_{2}\right)$ is the most widely used as a photocatalyst material because of its availability, low cost, chemical stability, non-toxicity and high activity in the photocatalysis process [4].At present, the commercially available $\mathrm{TiO}_{2}$ powders, Degussa P25 shows the highest photoactivity than that the others and thus it is the most commonly used in many kinds of photocatalytic applications [5,6]. Recently, loading of activated carbon (AC)adsorbent on $\mathrm{TiO}_{2}$ catalyst has drawn great attention since the high adsorption capability of AC can help to enrich organic substrate around the catalyst, promoting the pollutant transfer process and hence increasing the photocatalytic efficiency. The synergistic effect of adsorption by $\mathrm{AC}$ and photocatalytic decomposition by $\mathrm{TiO}_{2}$ has been observed in the degradation of several types of organic pollutants [7]. However, many problems with the use of photocatalyst material in powder form are wellknown; for example, it is difficulty in application to continuous flow systems, difficulty in separating the powder from the systems, difficulty in recovering and non-reusable of the catalyst after used [8].

Therefore, in this work, the immobilized $\mathrm{AC} / \mathrm{TiO}_{2} /$ Rubber (ACTR) composite sheets were fabricated to avoid of these above problems and to help eliminate the recovery of the catalyst. The activities of photodegradation of methylene blue(MB) dye under UV light irradiation by ACTR sheets were also studied. Methylene blue was used as a model dye in this researchdue to its being one of the most important basic dyes used in major dyeing and printing industries.

\section{Experimental}

\subsection{Chemicals and equipment}

Titanium dioxide (Degussa P25; A80/R20, Degussa, Germany),natural rubber latex (60\% HA, Chana Latex Co. Ltd., Songkhla, Thailand),activated carbon (AC, fine powder, Sigma-Aldrich, USA), ammonia solution $\left(\mathrm{NH}_{4} \mathrm{OH}, 28-30 \%\right.$, Baker, USA), and methylene blue (MB), (Fluka, USA)were used as received without further purification. Petri dish mold has 3.5 inch diameter. The crystalline phases of natural rubber, activated carbon and $\mathrm{TiO}_{2}$ on the ACTR sheets surface were identified by using X-ray diffraction (XRD) (X'Pert MPD, Phillips, the

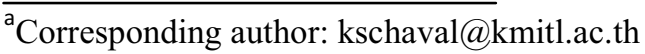


Netherlands) technique. The functional groups of natural rubber, activated carbon and $\mathrm{TiO}_{2}$ were investigated by using a attenuated total reflectionFourier transform infrared spectroscopy (ATR-FTIR) (Nicolet iS50, Thermo Fisher Scientific Inc., USA). The surface morphologies of the sheet samples were also characterized by using a scanning electron microscopy (SEM) (JEOL-JSM5800LV, Japan) attached with energy dispersive X-ray spectrometer (EDS) (Oxford ISIS 300).

\subsection{Preparation of activated carbon suspension}

The functionalized activated carbon wasprepared by a common treatment methodusing concentrated $\mathrm{HNO}_{3}$ and $\mathrm{H}_{2} \mathrm{SO}_{4}$ acid with the volume ratio of $3: 1$. All detailed of which has been described previously [9]. After that, the black aqueous suspension of activated carbon in water was easilyprepared by ultrasonicationmethod.

\subsection{Fabrication of ACTRcomposite sheets}

Thefabrication of ACTR sheets were fabricatedby a modifiedmethod of ours group, has been reported previously [10].For the fabrication of ACTR sheet, $0.03 \mathrm{~g}$ of $\mathrm{TiO}_{2}$ (Degussa P25) powder was mixed with $5 \mathrm{~mL}$ of ammonia solution and was stirred for 5 min after which 5 $\mathrm{mL}$ of natural rubber latex was added and then stirred for $10 \mathrm{~min}$. After that, $1 \mathrm{~mL}(1 \mathrm{mg} / \mathrm{mL})$ of activated carbon aqueous suspension was added in the mixture above and stirred for another $10 \mathrm{~min}$. Subsequently, the homogenized mixture was poured into a petri dish mold and left to dryness at room temperature (RT) for $15 \mathrm{~h}$ after which it was taken out from a mold, then reversed, and dried at RT about $2 \mathrm{~h}$ and ready for use. As such, the ACTR composite sheet with 3.3 wt $\%$ AC loading $\left(\mathrm{AC}: \mathrm{TiO}_{2} ; \mathrm{w} / \mathrm{w} \%\right)$ was fabricated. The ACTR sheet samples with $10.0 \mathrm{wt} \%$ and $16.7 \mathrm{wt} \% \mathrm{AC}$ loading were fabricated in the same manner under varying amounts of activated carbon suspension, $3 \mathrm{mg} / \mathrm{mL}$ and $5 \mathrm{mg} / \mathrm{mL}$, respectively. Forcomparison, the unloadingsheet $(0.0$ $\mathrm{wt} \%$ ) sample was also fabricated likewise but not adding of activated carbon.

\subsection{Photocatalyticstudies}

The photocatalytic activities of ACTR composite sheets were evaluated by monitoring decolorization of MB dye solution $\left(2.5 \times 10^{-5} \mathrm{M}\right)$ in a similar manner as has been described previously [10]. The concentrations of MB dye solution samples after photodegradation were analyzed using a UV-Visible spectrophotometer (Evolution 201, Thermo Scientific, USA). The percentages of photodegradation activities were calculated by equation (1),

$$
\% \text { Degradation of MB dye }=\frac{C_{0}-C_{t}}{C_{0}} \times 100 \text { (1) }
$$

where $C_{0}$ is the initial concentration of MB dye and $C_{t}$ is the concentration at a specific time interval of the collected samples.

\section{Results and Discussion}

The ACTR composite sheets were simply fabricated by mixing of fixed $\mathrm{TiO}_{2}$ suspension and natural rubber latex contents with the varying amounts of activated carbon suspension. The photographs of the obtained ACTR sheet samples are shown in Fig. 1.To the naked eyes, the surface of unloading (in Fig. 1a) has the white color whereas the loading of $\mathrm{AC}$, thecomposite sheets have the dark color. It is noted that the darkness on the surface of ACTR sheets increased with the increasing amount of AC loading (see in Fig. 1b-1c). This result indicatedthat the darker color of the surface has higher activated carbon particles covered on the sheet surface.

Fig. 2 illustrates the X-ray diffraction patterns of pristine $\mathrm{TiO}_{2}$ (Degussa P25) powder and the ACTR composite sheets. The diffraction peaks of anatase and rutile phases of $\mathrm{TiO}_{2}$ are marked with "A" and "R", respectively. As shown in the Fig. 2, a broad scattering peak around $2 \theta=$ $19^{\circ}$ of natural rubber matrix [11] were clearly observed in all the composite sheet samples. The XRD patterns of ACTR sheets (Fig. 2b-2e) were corresponded to the crystalline of pristine $\mathrm{TiO}_{2}$ powder (in Fig. 2a), whereas there was no activated carbon peak appeared on these which because of itsamorphous structure andvery low content $[2,12]$. In addition, the intensity of the anatase peak $\left(2 \theta=25.3^{\circ}\right)$ seem to be decreased with increasing amount of AC loading, i.e., the $16.5 \mathrm{wt} \%$ sheet sample (in Fig. 2e) has the lowest intensity compared with the other sheets. This may be due to the fact that the highest covering of AC particles on the sheet surface.
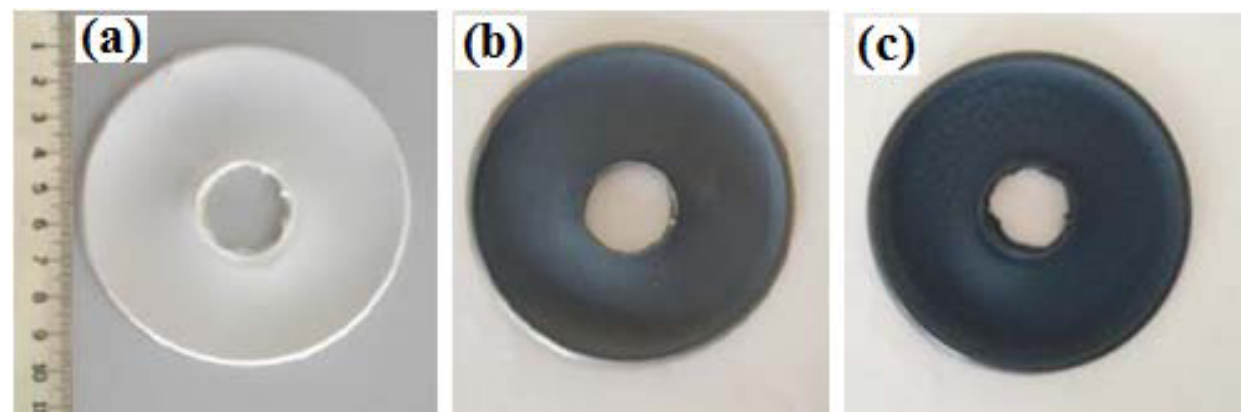

Fig. 1 Photographs of ACTR composite sheets; unloading (a) and loading of AC: (b) $10.0 \mathrm{wt} \%$ and (c) $16.7 \mathrm{wt} \%$. 


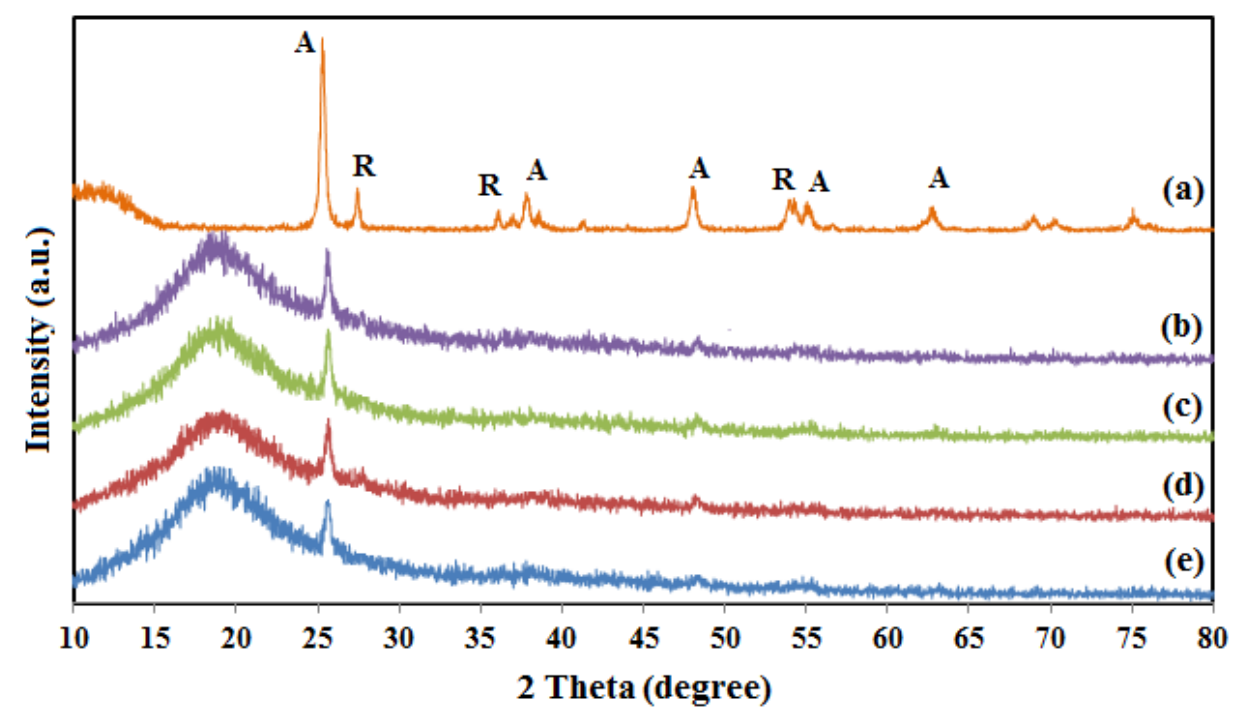

Fig. 2 XRD patterns of pristine $\mathrm{TiO}_{2}$ powder (a) and ACTR sheet samples; unloading (b) and loading of AC: (c) 3.3wt \%, (d) $10.0 \mathrm{wt} \%$ and (e) $16.5 \mathrm{wt} \%$.

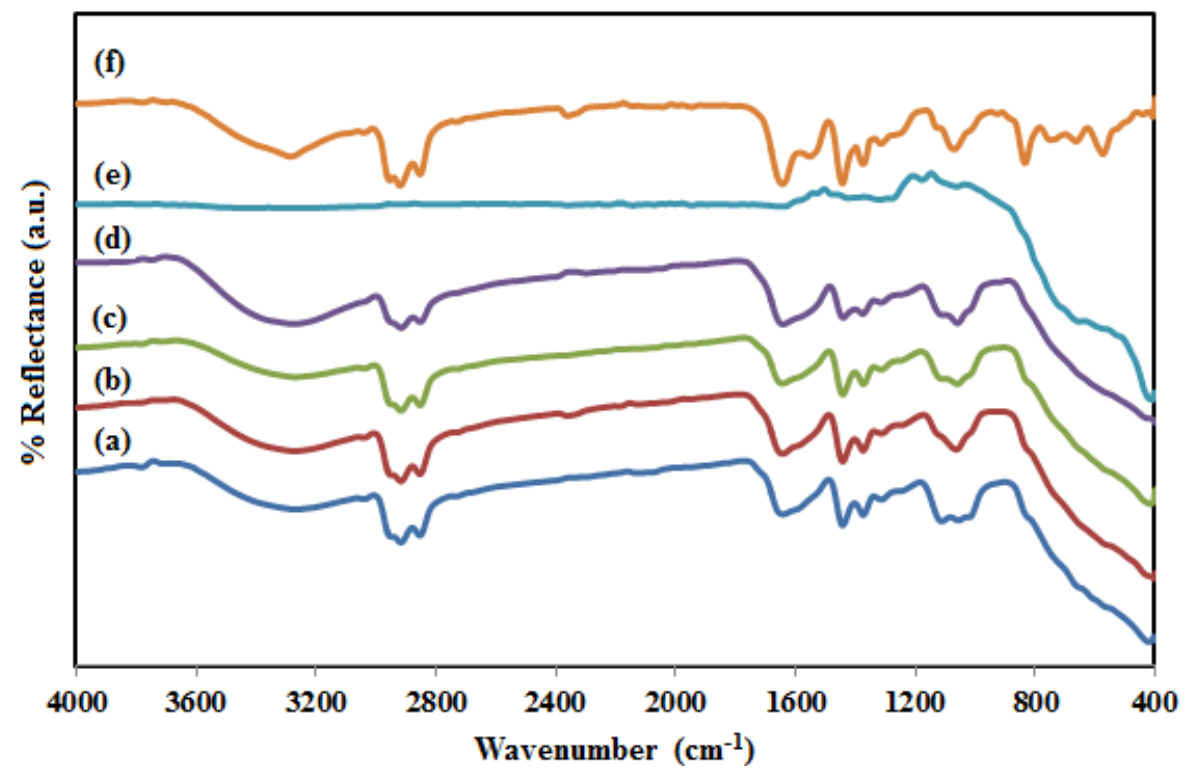

Fig. 3 ATR-FTIR spectra of ACTR sheet samples; unloading (a) and loading of AC: (b) $3.3 \mathrm{wt} \%$, (c) $10.0 \mathrm{wt} \%$ and (d) $16.5 \mathrm{wt} \%$. Pristine $\mathrm{TiO}_{2}$ powder (e) and natural rubber sheet (f).

Fig. 3 displays the FT-IR spectra of the natural rubber sheet, pristine $\mathrm{TiO}_{2}$ powder and all the ACTR sheet samples. In this work, the characteristic peaks of rubber sheet and $\mathrm{TiO}_{2}$ powder agree with the reported previously $[13,14]$. From this figure, it can be found that all of the absorption bands of ACTR sheets (in Fig. 3a-3d) are associated to the vibration modes of both pristine $\mathrm{TiO}_{2}(\mathrm{in}$ Fig. 3e) and natural rubber sheet (in Fig. 3f).The spectra of ACTR sheets under loading and unloading of AC were not different from each other. In addition, the vibration modes of activated carbon could not be observed on the surface of sheets with loading of AC (in Fig. 3b-3d). The reasons for invisibility of $\mathrm{AC}$ characteristic peaks in FTIR spectra may be due to a small amount of $\mathrm{AC}$ in compared with the large amount of rubber and $\mathrm{TiO}_{2}$ on the composite sheets.
The EDS analysis was carried out to investigate the presence of elements in the ACTR sheet surface. For all samples, only three elements were detected in these sheets including carbon, oxygen, and titanium. Fig. 4 displays the EDS mapping of theACTR sheet samples.In comparison, the sheet surface ofunloading AC (in Fig. 4a) shows more distribution of $\mathrm{Ti}\left(\mathrm{TiO}_{2}\right.$ particles $)$ atoms, but less carbon atoms on the surfacethan the loading sheet (in Fig. 4b-4c). In contrast, the ACTR sheets in the case of AC loading have high distribution of carbon atom on the sheet surface, especially loading as $16.7 \mathrm{wt} \%$ (see in fig. $4 \mathrm{c})$. It is evident that there was a large amount of AC particles on the sheet surface of high content AC loading. 

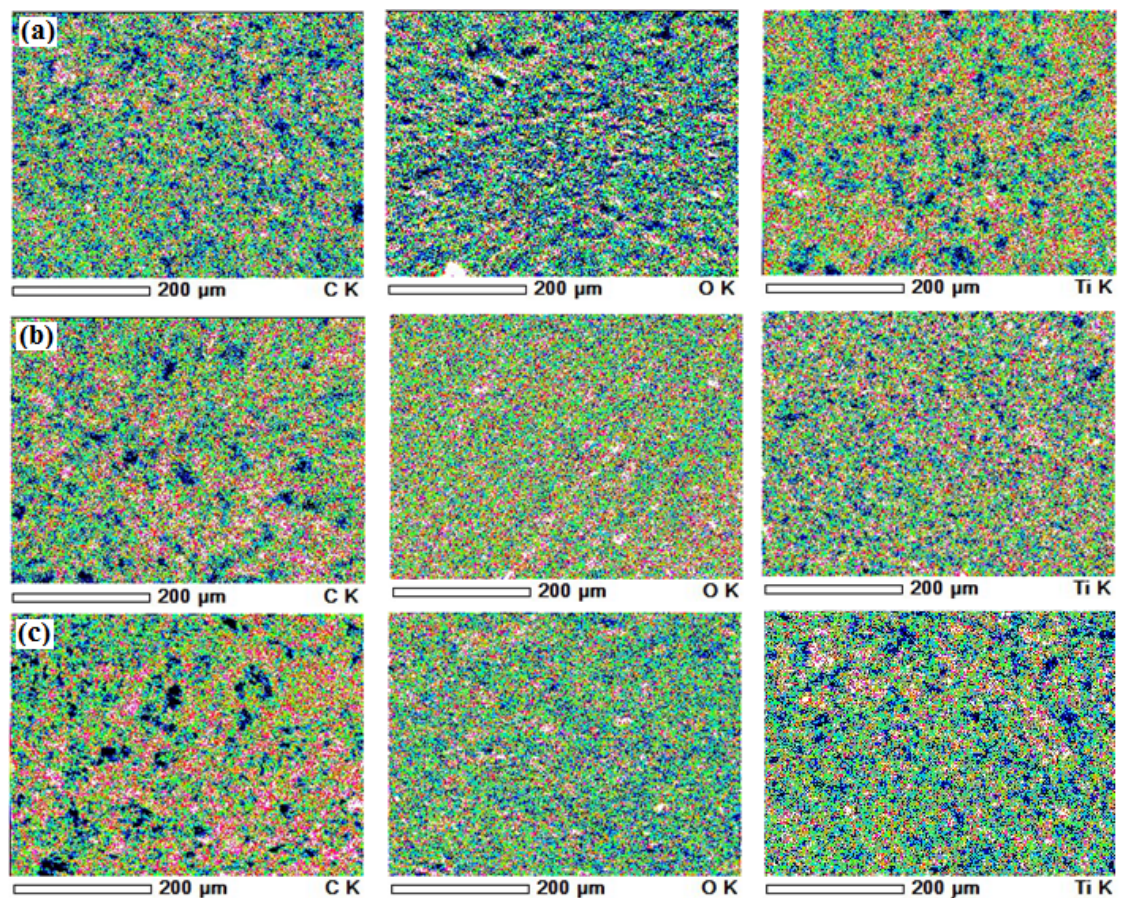

Fig. 4EDS mapping of ACTR sheet samples; unloading (a) and loading of AC: $10.0 \mathrm{wt} \%$ (b) and $16.5 \mathrm{wt} \%$ (c).
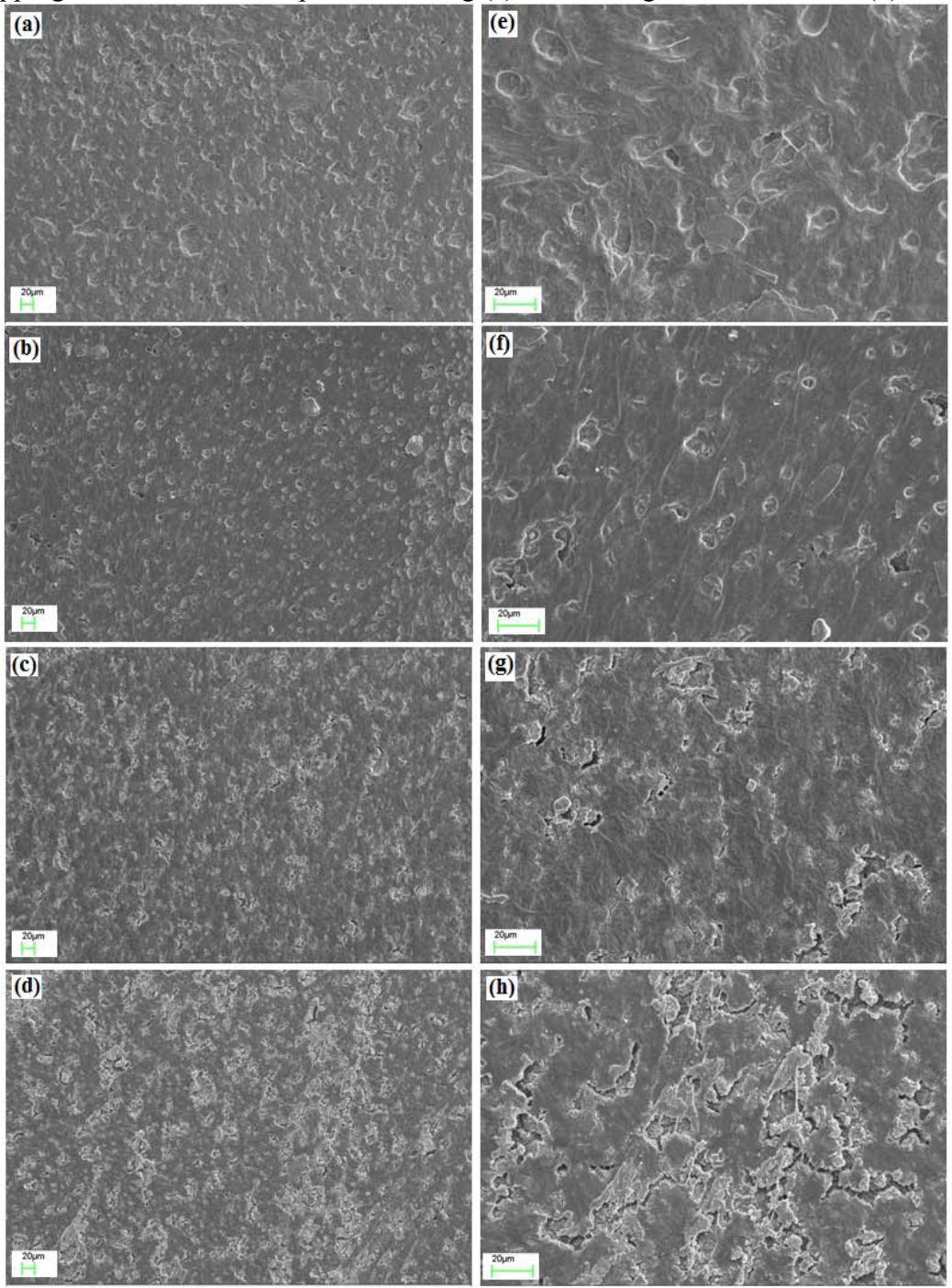

Fig. 5SEM images of ACTR sheet samples; low magnification_ $\times 150$ (left column) and high magnification_ $\times 500$ (right column) of unloading (a and e) and loading of $\mathrm{AC}: 3.3 \mathrm{wt} \%(\mathrm{~b}$ and $\mathrm{f}), 10.0 \mathrm{wt} \%(\mathrm{c}$ and $\mathrm{g})$ and $16.5 \mathrm{wt} \%(\mathrm{~d}$ and $\mathrm{h})$. 
Fig. 5 shows the surface morphologies of all ACTR composite sheet samples. From the figure, it can be observed that a certain degree of roughness on the sheet surface became rougher with increasing amount of activated carbon loading. The surface of ACTR sheet sample (Fig. 5a and 5e), unloading AC has the smoothest surface. On the other hand, the highest rough surface can be found in the case of the highest activated carbon loading (in Fig. 5d and 5h). It is implied that there was a large amount of activated carbon particles which high agglomerate and cover on the sheet surface. This corresponds to the EDSmapping results are shown in Fig. 4.

The photodegradation of MB dye solution by the ACTR sheet catalysts were studied under UV light irradiation for $3 \mathrm{~h}$, and the results are shown in Fig. 6a and $6 \mathrm{~b}$. It can be seen that the MB dye was completely degraded by the compositesheet sample under UV light irradiation causing the bright-blue color of $\mathrm{MB}$ dye aqueous solution to colorless solution (in Fig. 6a). From the Fig. $6 \mathrm{~b}$, it can be found that the ACTR sheet sample, $10.0 \%$ wtactivated carbon loading has the highest photodegradation efficiency than the other sheets. The photocatalytic degradation by using $\mathrm{TiO}_{2}$ along with $\mathrm{AC}$ was more effective and faster activity for removing $\mathrm{MB}$ dye than the $\mathrm{TiO}_{2}$ alone. The reason of this is due to the fact that it is relatively with the synergistic effect of wellcombined titanium dioxide photocatalyst and activated carbon adsorbent particles are fitted on the sheet surface, enhancing the photodegradation of dye $[2,15,16]$. (a)

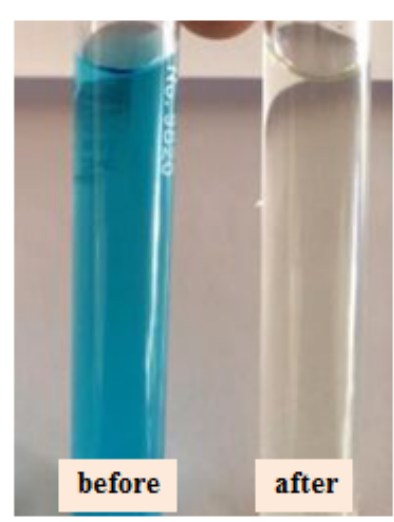

(b)

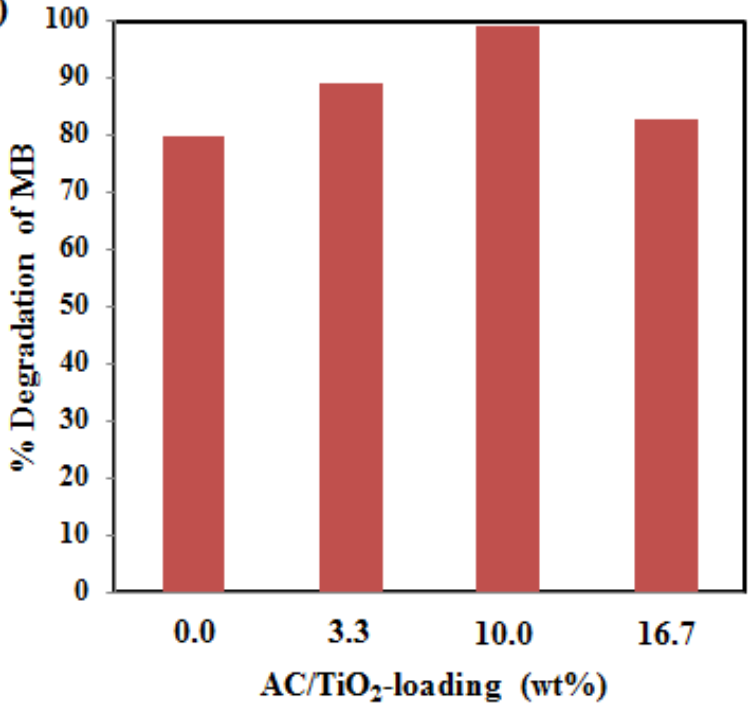

Fig.6 The efficiencies of photocatalytic degradation of MB dye solution under UV light irradiation for $3 \mathrm{~h}$ by the ACTR composite sheet samples.

\section{Conclusions}

In summary, we have successfully fabricated the ACTR composite sheet catalyst using a simple and low cost method. The fabricated ACTRcomposite sheets show both the photocatalytic property of pristine $\mathrm{TiO}_{2}$ particles along with the adsorb-ability of AC,resulting higherthe photodegrading of $\mathrm{MB}$ dye solution under UV light irradiation than the $\mathrm{TiO}_{2}$ alone.Although, the ACTR sheet in this work appears to be less efficiency than the loose powder of $\mathrm{TiO}_{2}$, it has one promising advantage on the easily recovery after the use. Thus, the easy use and recovery of the sheet should be attractive to the water treatment in industry as it helps keep the operation cost low.

\section{Acknowledgment}

The authors would like to thanks the Faculty of Science, King Mongkut's Institute of Technology Ladkrabang for the financial supported.

\section{References}

1. R.C. Wang, K.S. Fan and J.S. Chang: J. Taiwan Inst. Chem. Eng.Vol. 40 (2009), p. 533

2. M. AsilturkandS. Sener: Chem. Eng. J. Vol. 180 (2012), p. 354

3. Y. Ao, J. Xu, D. Fu, X. Shen and C. Yuan: Appl. Surf. Sci. Vol. 254 (2008), p.4001

4. J. Kim and W.Choi: Appl. Catal. B Environ. Vol. 106 (2011), p. 39

5. X. Qin, L. Jing, G. Tian, Y. Qu and Y. Feng: J. Hazard. Mater. Vol. 172 (2009), p. 1168

6. M. Nawi and S. Md. Zain: Appl. Surf. Sci. Vol. 258 (2012), p. 6148

7. M. Ouzzine, A.J. Romero-Anaya, M.A. LilloRodenas and A. Linares-Solano: Carbon Vol. 67 (2014), p. 114 
8. L. Lopez, W. A. Daoud, D. Dutta, B.C. Panther and T.W. Turney: Appl. Surf. Sci. Vol. 265(2013),p.162

9. C.C. Li, J.L. Lin, S.J. Huang, J.T. Lee and C.H.Chen: Colloids Surf. A: Physicochem. Eng.AspectsVol. 295 (2007), p. 275

10. C. Sriwong, S. Wongnawa and O. Patarapaiboolchai: Catal. Commun. Vol. 9 (2008), p. 213

11. C. Sriwong, S. Wongnawa and O. Patarapaiboolchai: Chem. Eng. J. Vol. 191 (2012), p. 210

12. X. Wang, X. Xue, Q. Li, M. Zhang and J. Yang: Mater. Letters Vol. 88 (2012), p. 79
13. M. Valera-Zaragoza, A. Yescas-Yescas, E.A. Juarez-Arellano, A. Aguirre, A. Aparicio- Saguilan, E. Ramirez-Vargas, S. Sepulveda-Guzman and S. Sanchez-Valdes: Polym. Bull. Vol. 71 (2014), p. 1295

14. C. Wang, H. Shi and Y.Li: Appl. Surf. Sci. Vol. 258 (2012), p. 4328

15. S. Ragupathy, K. Raghu and P.Prabu: Spectrochim. Acta Part A Vol. 138 (2015), p. 314

16. X. Wang, Y. Liu, Z. Hu, Y. Chen, W. Liu and G. Zhao: J. Hazard. Mater. Vol. 169 (2009), p. 1061 